\title{
NOTAS SOBRE A NATUREZA-MORTA E NATUREZA COMO SUPORTE NA CONTEMPORANEIDADE
}

\author{
Milena Duarte Corrêa - Universidade Federal de Santa Maria \\ milenadc27@gmail.com
}

\begin{abstract}
RESUMO
O presente artigo foi desenvolvido a partir de uma pesquisa em andamento iniciada no ano de 2015. Esta, intitulada "Contestações e Subversões na Representação Artística dos Objetos", tem por objetivo investigar as relações que podem ser estabelecidas com o gênero milenar da história da arte -natureza-morta- e, posteriormente, a Natureza como suporte para arte da contemporaneidade. O projeto vem se desenvolvendo enquanto pesquisa e está sendo aplicado nos estágios da licenciatura do curso de artes visuais em escolas da rede pública.
\end{abstract}

Palavras-chave: Natureza-morta; Arte; História; Contemporaneidade; Ressignificações.

\section{INTRODUÇÃO}

Este projeto de ensino e pesquisa iniciado na disciplina de Prática Educacional IV, componente da grade curricular do curso de Artes Visuais - Licenciatura Plena em Desenho e Plástica da Universidade Federal de Santa Maria, foi planejado com intuito de permear as primeiras experiências docentes no Estágio Supervisionado. A escolha da temática para a pesquisa parte de um interesse pessoal, bem como uma investigação pictórica a partir do gênero da natureza-morta. A poética em exercício trata de um aprofundamento de dois anos na pintura de naturezas-mortas, como também, na linguagem da serigrafia artística. Partindo do desenvolvimento e constante investigação plástica, sentiu-se necessário transformar o estudo em uma pesquisa teórica que abrangesse as questões inquietantes por detrás da pintura e representação dos objetos. Tornou-se, assim, a linha de pesquisa que hoje contempla a aplicação dos estágios e, posteriormente, abarcará projetos para além da academia. Acredita-se que o tema se mostra como dispositivo de potência para tecer as relações entre a história -como um registro sensível dos acontecimentos e, sobretudo, o resgate de trajetória- e a arte contemporânea - como crítica social, possibilidade de reflexão, (des)construção de conceitos e (re)significações. 


\section{O GÊNERO MILENAR}

Recorrendo-se à história da arte, refletindo-se filosófica e esteticamente sobre a natureza-morta, se pode criar muitas aproximações, tanto quanto distanciamentos, fazeres e saberes contrários, um campo de fricções. Seu conceito descende da palavra holandesa "stilleven", em inglês, still life, que "se refere a uma natureza parada, inerte, composta de objetos inanimados" (CANTON, 2004, p. 11). Partindo de diferentes motivações somadas ao tratamento pictórico adequado, compõem o sentido latente das obras. Inicialmente, a temática não tinha preocupação em contar uma história, expressar ou indagar ideias, o interesse dos artistas era no próprio objeto representado - sua cor, textura, volume, superfície e, sobretudo, a relação entre eles. Entretanto, depois do Romantismo, já no século XIX, a natureza-morta começou a alcançar um novo lugar no seio da arte. Partindo do princípio que todos os seres e/ou objetos podem ser dignos de atenção, possibilitou que a temática se desvencilhasse de valores alegóricos e simbólicos, em favor de valores estéticos e compositivos. Um exemplo dessa ressignificação foi a postura de Cezánne diante do modelo de natureza-morta. Segundo Canton (2004) ela desabrochou como objeto de desejo encenado, composto numa moldura de tela para se tornar um potente exercício de cor, forma, luz e sombra, perspectiva e textura.

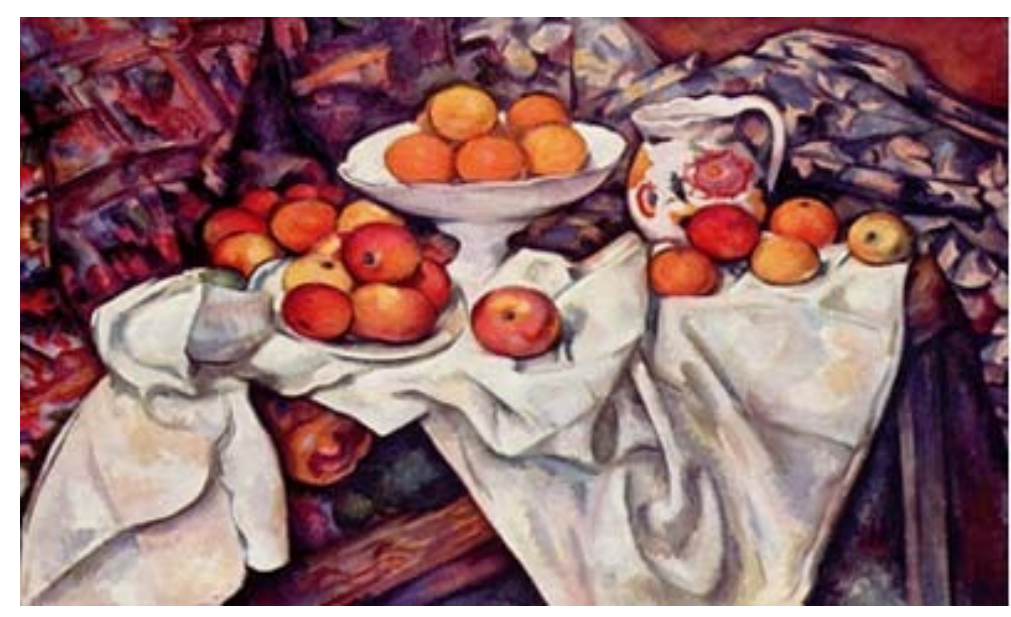

Figura 1: Natureza-morta com maçãs e laranjas, Museu d'Orsay, Paris. 1895-1900. Paul Cézanne. Óleo sobre tela, 74 x $93 \mathrm{~cm}$.

Fonte: http://paul-cezanne.tumblr.com/post/35008391009/natureza-morta-comma\% $\%$ C $\%$ A $7 \% \mathrm{C} 3 \% \mathrm{~A} 3 \mathrm{~s}-\mathrm{e}-\mathrm{laranjas}$

"Cézanne escolhera os seus motivos para estudar alguns problemas específicos que queria resolver. Sabemos que ele estava fascinado pela relação da cor com a modelação. Um sólido redondo, brilhante e colorido, como uma maçã, era um motivo ideal para explorar essa questão". (GOMBRICH, 1995. p. 543.)

Como defende Gombrich, Cezánne estudava a disposição dos objetos, a geometria dos volumes e fazia da cor a riqueza necessária para que a forma atingisse sua plenitude. Sua contribuição à história da arte é decisiva, principalmente em suas novas 
possibilidades de criação que começariam a eclodir no decurso do século XX. Sendo assim, ele é um dos artistas que está permanentemente a ser descoberto, um mestre que revolucionou a arte de seu tempo, de seus contemporâneos e desdobramentos futuros.

\section{O Decorrer da História}

Num salto para o século XX, verte no modernismo o que mais se propagou no movimento: o cubismo. O objetivo naturalista de pintar os objetos como eles se mostram ao observador foi abandonado; no cubismo os artistas procuraram transmitir a existência do objeto no tempo e no espaço representando-o em diferentes perspectivas. Objetos estáticos a partir de pontos de vista em movimento, capturando a composição em suas múltiplas facetas. O principal precursor quando se fala em cubismo é Pablo Picasso. Ele dizia não capturar a imagem como uma câmera ou olho, mas como a mente a processava.

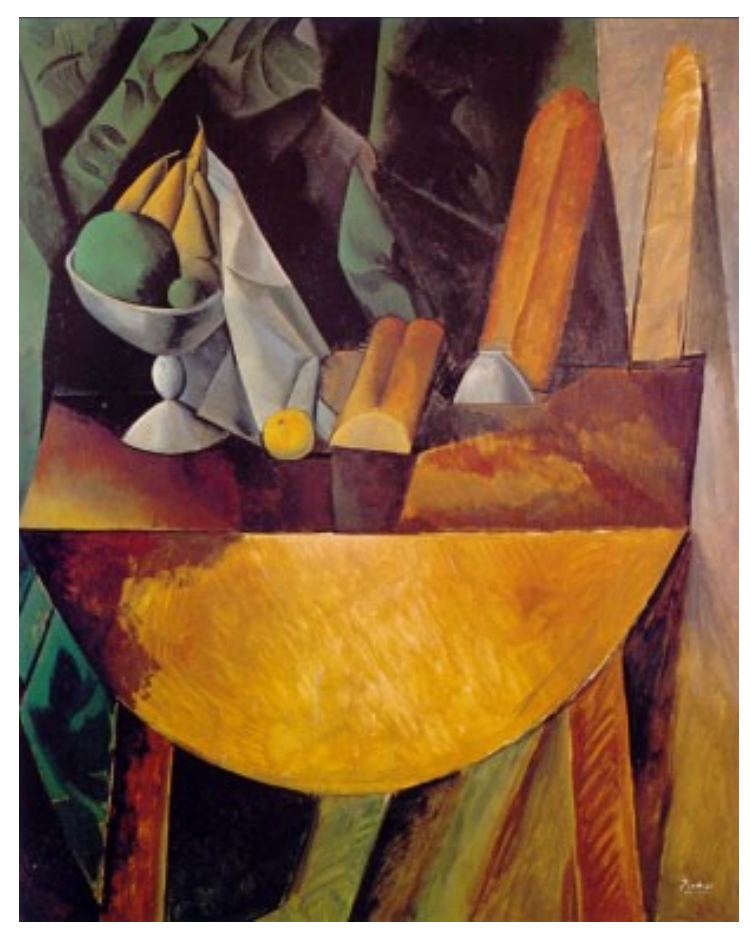

Figura 2: Fruteira e pão sobre uma mesa, Kunstmuseum, Basiléia. 1909. Pablo Picasso. Óleo sobre tela, 164 x $132,5 \mathrm{~cm}$.

Fonte: WALTHER, Ingo. Picasso. Germany: Taschen, 2000. p. 36.

"Talvez os nossos temas sejam outros, pois que introduzimos na pintura objetos e formas que anteriormente eram ignorados. Mantemos os olhos abertos - e o espírito- para o mundo que nos rodeia. Damos a forma e a cor o significado que lhes compete, tanto quanto nos é permitido reconhecê-lo; nos nossos temas mantemos a alegria da descoberta, o prazer do inesperado, o nosso 
tema em sí deve ser uma fonte de interesse". Picasso apud WALTHER, 2000, p. 44.

Picasso desenvolveu sua poética de maneira distinta a tudo que estava sendo realizado na época rompendo com padrões estéticos que primavam pela representação da forma naturalista e fiel dos objetos. Diz-se que no cubismo o mais importante era aquilo que se queria fazer, a intenção que se tinha.

Passado um século, mediante todos os deslocamentos contextuais, históricos e, sobretudo, artísticos, a natureza-morta, assim como os demais gêneros, passam a fazer parte da produção de arte contemporânea. Uma análise estética da temática em questão mostra que além de não ter morrido, a natureza-morta deixa de ser um gênero de representação de objetos e passa a desempenhar um papel conceitual nos procedimentos operatórios, ou seja, absorve a tradição pictórica para em seguida trabalhar materiais, suportes e técnicas que antes não seriam pensadas. Segundo Galleguer (2002) percebe-se a proliferação deste gênero em suas várias formas de manifestação na arte contemporânea: desde a surreal até a meramente estranha, desde a contemplação do estático até como o tempo e o movimento afetam os objetos comuns que nos rodeiam. Como se sabe, na contemporaneidade, a arte não aparece apenas em uma galeria destacada por uma moldura, expande-se em uma proliferação de suportes.

Ressignificações inseridas ao conceito, possibilitam que na contemporaneidade a Natureza possa ser o suporte para composições. Sejam elas construídas para pensar a arte como crítica social/ambiental, ou, pelo anseio de uma produção que vá além do olhar do observador, sobretudo para que este participe, questione, construa seus significados, aproprie-se da obra. Como exemplo dessa possibilidade de produção artística contemporânea, tem-se o trabalho do paulistano Eduardo Srur que faz da cidade e dos espaços urbanos a sua galeria. Sua intervenção com garrafas pet gigantes promove um maior engajamento na arte para todas as camadas sociais e rompe com os limites do sistema artístico.

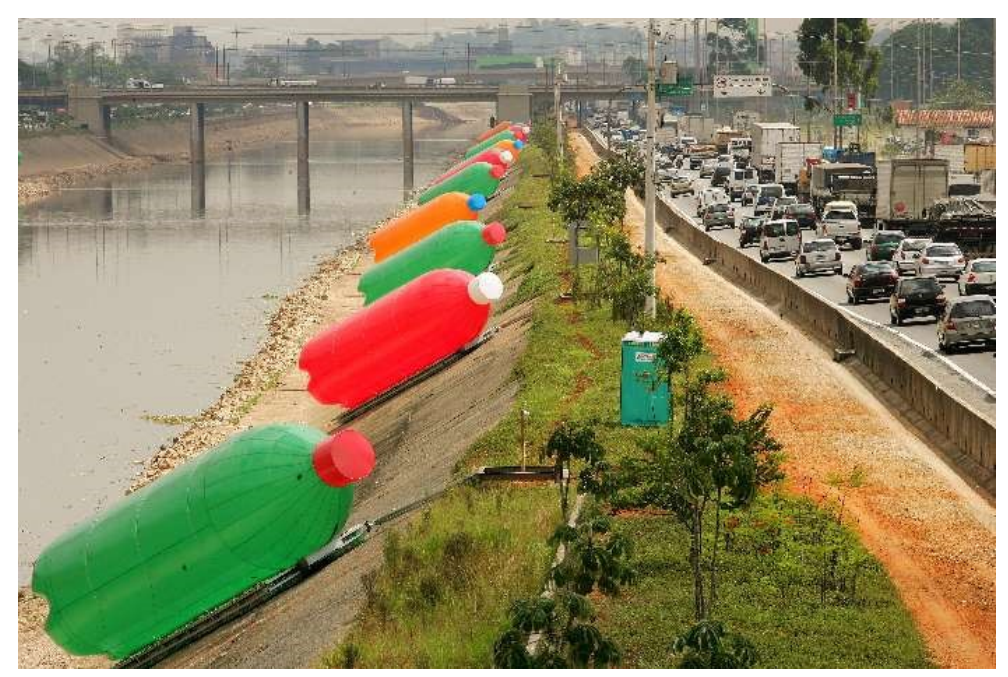

Figura 3: Pets. Eduardo Srur. 20 peças de 12, 3,5 m. cada. Margens do concreto do Rio Tietê, São Paulo, 2008.

Fonte: http://www.eduardosrur.com.br/intervencoes/pets 
A instalação tem como objetivo conscientizar e inquietar o público para o cuidado com o meio ambiente. Em suas palavras: "Eu trabalho com a alteração da paisagem urbana e me interessa o resultado que vai ter no espectador. Desenvolvo meu trabalho pensando na reação do outro, como ele vai reagir.... Quero tirá-lo de uma anestesia e fazê-lo refletir, pensar. Os locais eu escolho de acordo com o espaço, pela intuição ou estratégia".

O segundo exemplo é o inglês Jason deCaires Taylor, apaixonado por arte e água resolveu unir as duas coisas e montar sua "galeria de arte submarina". O cimento marinho esculpido em tamanhos grandes - um deles uma composição de objetos- é colocado no fundo do mar para que as esculturas se transformem em recifes artificiais. Assim, a obra inicial é pensada e produzida pelo artista e deixada para que o mar se aproprie e o tempo faça sua interferência a modificando constantemente.

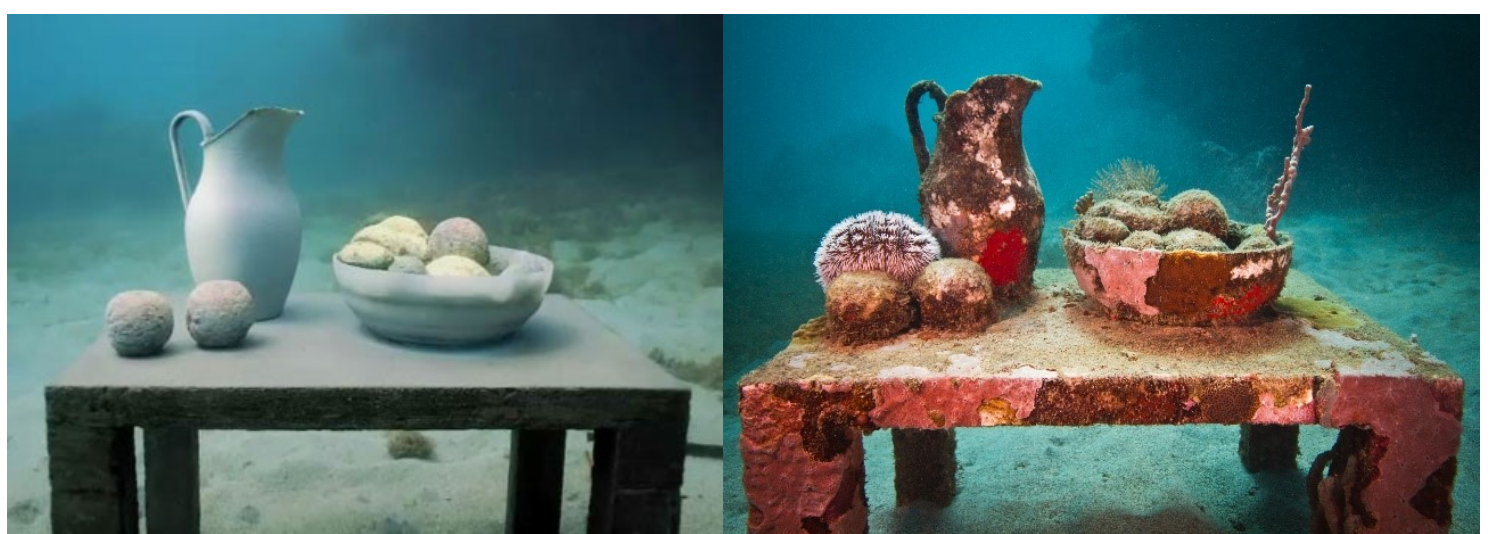

Figura 4: A evolução silenciosa/ Un Still Life. Jason deCaires Taylor. Profundidade: 8m. Granada, Índias Ocidentais.

Fonte: http://www.underwatersculpture.com/sculptures

Para Taylor a ideia é criar um gigante recife artificial que se torne o novo habitat de milhares de espécies marinhas. Em suas palavras: "Eu sempre trabalhei produzindo arte para as mais diversas paisagens - campos, parques, áreas perto do mar. Paralelamente, eu me interessava muito por mergulho. Mas ao mesmo tempo em que eu fazia esculturas, tinha uma sensação que estava entulhando o mundo com mais objetos, todos na terra. Parecia sem sentido, mas eu me sentia assim, ao produzir mais uma obra de arte." - Entrevista exclusiva ao Planeta Sustentável, 2010.

Diante dos dois exemplos acima, vê-se que a proposta contemporânea envolve muito mais que uma apreciação de arte, mas uma arte pautada pela experiência de dar novos sentidos, uma construção de saberes a partir de uma experimentação, daquilo que afeta, que reverbera. 


\section{CONCLUSÃO}

Diante do exposto, partindo dessa e de outras investigações, existe a necessidade de pesquisas em arte que renunciem a "tendência vanguardista"- que abandona o que era tido como verdade para priorizar o atual. Nessa pesquisa, por exemplo, mostra-se o quanto a história da arte com suas concepções e princípios são o que respaldam várias das produções de arte na contemporaneidade; por isso é possível e, especialmente, necessário, oportunizar essas interlocuções que potencializam a produção artística. As conexões e afinidades que se pode estabelecer entre o gênero da natureza-morta - que por séculos teve suas alterações - e a Natureza como suporte para correntes contemporâneas começam no que diz respeito ao termo, a familiaridade entre as palavras, uma vez que toda arte, histórica e contemporânea sempre diz algo essencial, de modo que sua datação é um mero detalhe e o que importa de modo real é a sua aproximação e relação com o público (COELHO, 2008.) o que todas, independentemente de seus contextos, efetivaram com louvor.

\section{REFERÊNCIAS}

CANTON, Kátia. Natureza-Morta. In. MUSEU DE ARTE CONTEMPORÂNEA/SESI. Natureza-morta: Still Life. São Paulo, 2004

GOMBRICH, Ernest. H. A História da Arte. Tradução: Álvaro Cabral: Rio de Janeiro: Record, 2007. 688 pg.

WALTHER, Ingo. Picasso. 2 ed. Lisboa: Taschen, 2000. 95 pg.

GALLEGUER, Ann(Org). Still Life Natureza-Morta. Londres: Art Library, 2002. Catálogo

COELHO, Teixeira(Org.). Natureza-Morta. Museu de Arte de São Paulo Assis Chateaubriand - MASP. São Paulo: 2008. Catálogo

STEPHEN, Farthing. Tudo sobre arte. 1.ed. Rio de Janeiro: Sextante, 2010. 563 pg. LITTLE, Stephen. Ismos para entender a arte. 1.ed. São Paulo: Globo, 2010. 159 pg. CAMARGO, Suzana - A evolução silenciosa de Jason deCaires Taylor. Disponível em < http://planetasustentavel.abril.com.br/noticia/ambiente/evolucao-silenciosa-jasondecaires-taylor-610712.shtml> acesso em 13/11/2016 às 08h45min. 